\title{
Ultra Grain Refining and Decomposition of Oxide during Super-heavy Deformation in Oxide Dispersion Ferritic Stainless Steel Powder
}

\author{
Yuuji KIMURA, Setsuo TAKAKI, Shinichi SUEJIMA, ${ }^{1)}$ Ryuji UEMORI ${ }^{2)}$ and Hiroshi TAMEHIRO ${ }^{2)}$
}

Materials Engineering Group, Department of Materials Physics and Chemistry, Graduate School of Engineering, Kyushu University, Hakozaki, Higashi-ku, Fukuoka, Fukuoka-ken, 812-8581 Japan.

1) Formerly Graduate Student, Kyushu University. Now at Mizushima Works, Kawasaki Steel Corporation, Mizushima, Kurashiki, Okayama-ken, 712-8511 Japan. $\quad$ 2) Steel Research Laboratories, Nippon Steel Corporation, Shintomi, Futtsu, Chibaken, 293-8511 Japan.

(Received on July 27, 1998; accepted in final form on October 8, 1998)

\begin{abstract}
Mechanical milling using a high energy planetary ball mill was applied to the powder mixtures of iron, chromium and yttria $\left(\mathrm{Y}_{2} \mathrm{O}_{3}\right)\left(\mathrm{Fe}-24\right.$ mass $\% \mathrm{Cr}-0-15$ mass $\left.\% \mathrm{Y}_{2} \mathrm{O}_{3}\right)$ to introduce a very large strain into the iron-base matrix, and microstructural changes during mechanical milling were investigated in relation to decomposition behavior of $\mathrm{Y}_{2} \mathrm{O}_{3}$ particles. Mechanical milling of more than $36 \mathrm{ks}$ was long enough to allow the mechanical alloying of iron and chromium powders. After the milling of $36 \mathrm{ks}$, ultrafine bcc crystalline grains of 10 to $20 \mathrm{~nm}$ were formed within $\mathrm{Fe}-24$ mass $\% \mathrm{Cr}-15$ mass $\% \mathrm{Y}_{2} \mathrm{O}_{3}$ powder mixture and 15 mass $\%$ of $\mathrm{Y}_{2} \mathrm{O}_{3}$ particles were almost decomposed. The resultant powder mixture markedly hardened to about $1000 \mathrm{Hv}$. The decomposition of $\mathrm{Y}_{2} \mathrm{O}_{3}$ particles can be explained as being due to the formation of an amorphous grain boundary layer where yttrium and oxygen atoms are enriched. As a result, it is proposed that, for the dissolution of $\mathrm{Y}_{2} \mathrm{O}_{3}, \mathrm{bcc}$ crystalline grains should be refined to a nanometric size to provide a sufficient volume fraction of the grain boundary layer, and that $\mathrm{Y}_{2} \mathrm{O}_{3}$ particles should be crushed to several nanometers to produce the driving force for the decomposition of $\mathrm{Y}_{2} \mathrm{O}_{3}$ particles.
\end{abstract}

KEY WORDS: powder metallurgy; mechanical milling; plastic deformation; oxide dispersion strengthened alloy; decomposition; dissolution; segregation; precipitation; grain boundary; amorphous.

\section{Introduction}

When metal powder and oxide particles are placed together with hard balls in a pot and tumbled or agitated, very large strain is introduced into the metal powder, and the physical energy of tumbling or agitation causes not only fine mixing but also alloying of the constituent materials. Regardless of whether or not alloying is involved, milling powder materials using a high-energy ball mill is called mechanical milling in a broad sense. Milling for the purpose of alloying is referred to as mechanical alloying to distinguish it from mechanical milling. Mechanical alloying was developed by Benjamin et al. ${ }^{1}$ in 1970 as a technique for manufacturing nickel-based superalloys strengthened by dispersion of fine oxide particles, or oxide-dispersion-strengthened (ODS) alloys. Oxides with a low solubility limit in metals are difficult to finely disperse in a metal matrix by conventional processes, such as melting, casting, and working. The production of ODS alloys was made possible only by the consolidation of a mixture obtained by the mechanical milling of metal and oxide powders. Iron-based, ${ }^{2)}$ aluminum-based, ${ }^{3)}$ and various other ODS alloys were subsequently developed by similar processes. ODS ferritic stainless steel is being developed as a material for construction of fuel cladding tubes for future large fast breeder reactors because it has a small co- efficient of thermal expansion, excellent hot corrosion resistance and creep rupture strength, and good nuclear irradiation resistance. ${ }^{4)}$ The primary purpose of mechanical milling has been to produce a fine dispersion of oxide particles in a metal matrix. Recently, Nomura et al. $^{5)}$ suggested the possibility of oxide powder being not only finely divided but also decomposed in the metal matrix. This decomposition behavior of oxides is a phenomenon that cannot be explained by classical thermodynamics. Elucidation of this behavior mechanism is extremely important from a microstructural control point of view.

This study selected as the matrix metal a 24 mass $\%$ chromium ferritic steel with a bcc phase stable up to a level right below the melting point, not only from a practical standpoint but also to avoid phenomenological complexity due to the fcc-bcc phase transformation that occurs upon heating and cooling. Ytria $\left(\mathrm{Y}_{2} \mathrm{O}_{3}\right)$, which is thermally stable up to a high temperature level and commonly used in ODS alloys, was selected as the dispersoid. A maximum of 15 mass $\% \mathrm{Y}_{2} \mathrm{O}_{3}$ was added this steel to produce a mixed powder composed of $\mathrm{Fe}$, 24 mass $\% \mathrm{Cr}$, and 0 to 15 mass $\% \mathrm{Y}_{2} \mathrm{O}_{3}$. The powder mixture was then mechanically milled. The changes in the microstructure of the matrix and the morphology of the $\mathrm{Y}_{2} \mathrm{O}_{3}$ particles during mechanical milling were then investigated. As a result, the decomposition of oxide 
Table 1. Chemical compositions of powders mechanically milled for $360 \mathrm{ks}$. (mass\%)

\begin{tabular}{ccccl}
\hline $\mathrm{Y}_{2} \mathrm{O}_{3}$ & $\mathrm{Cr}$ & $\mathrm{C}$ & $\mathrm{N}$ & $\mathrm{Fe}$ \\
\hline without & 23.32 & 0.016 & - & bal. \\
$5 \%$ & 24.27 & 0.016 & 0.0283 & bal. \\
$10 \%$ & 24.12 & 0.013 & 0.0107 & bal. \\
$15 \%$ & 24.02 & 0.013 & 0.0132 & bal. \\
\hline
\end{tabular}

* Oxygen contamination from $\mathrm{Fe}$ and $\mathrm{Cr}$ powders; about $0.4 \%$.

particles during super-heavy deformation was confirmed, and its mechanism was clarified.

\section{Experimental Methods}

The initial powders used were reduced iron powder ( $99.2 \mathrm{mass} \% \mathrm{Fe}$ and a particle size of $-100 \mathrm{mesh}$ ), electrolytic chromium powder $(99.7$ mass\% $\mathrm{Cr}$ and a particle size of $-200 \mathrm{mesh}$ ), and high-purity fine yttria powder $\left(99.9\right.$ mass $\% \quad \mathrm{Y}_{2} \mathrm{O}_{3}$ and an average particle size of $0.05 \mu \mathrm{m})$. The amount of oxygen contamination from the iron and chromium powders was about 0.4 mass $\%$. The initial powders were mixed in weight proportions of $\mathrm{Fe}, 24 \mathrm{mass} \% \mathrm{Cr}$, and 0 to 15 mass $\% \mathrm{Y}_{2} \mathrm{O}_{3}$, placed together with 300 steel balls of $10 \mathrm{~mm}$ in diameter in a SUS304 pot (of 0.42 liter volume), and mechanically milled in an argon atmosphere in a planetary ball mill for a maximum period of $360 \mathrm{ks}$. The weight ratio of the steel balls to the powder was 20. The chemical compositions of the powders mechanically milled for $360 \mathrm{ks}$ are given in Table 1. The chromium content of these powders was about 24 mass $\%$ after $360 \mathrm{ks}$ of mechanical milling. The contents of the interstitial elements carbon and nitrogen were 0.016 mass $\%$ and 0.028 mass $\%$, respectively. This means that the effect of contamination on the microstructure of the powders during mechanical milling is small enough to be ignored. The mechanically milled powders were annealed in a hydrogen atmosphere as required to prevent oxidation.

The microstructures of the mechanically milled powders were observed by transmission electron microscopy (TEM) with an acceleration voltage of $200 \mathrm{kV}$ and field emission-transmission electron microscopy (FE-TEM). TEM thin-foil specimens were prepared from samples of the mechanically milled powders consolidated by the cold pressing method developed by Ameyama et al. ${ }^{6)}$ Heat treatment was performed after this consolidation. The thin-foil specimens were prepared by the twin-jet polishing method under the following conditions: an electrolyte solution of $10 \%$ perchloric acid and $90 \%$ acetic acid; and an electrolytic current of about $90 \mathrm{~mA}$. The crystalline grain size of the matrix and the size of the $\mathrm{Y}_{2} \mathrm{O}_{3}$ particles were measured in the dark-field images of the TEM. $\mathrm{X}$-ray diffraction was performed by using cobalt as the target at an acceleration voltage of $45 \mathrm{kV}$ and a current of $60 \mathrm{~mA}$. The lattice parameter $\left(a_{0}\right)$ of the matrix was obtained by plotting and lineally fitting with respect to $\cos 2 \theta$ the lattice parameter $(a)$ obtained from the peak positions $(2 \theta)$ of the three planes $(200)$, (211) and (220) of the bcc phase and extrapolating it to a value at $\theta=\pi / 2$. The $\mathrm{X}$-ray diffraction lines were decomposed into $K_{\alpha 1}$ and $K_{\alpha 2}$ components by the method of Rachinger, ${ }^{7)}$ and crystallite-size $(D$; the size of crystalline grain or dislocation cell within powder particles) and local strain ( $\varepsilon$; internal elastic strain produced by dislocations, etc.) were estimated on the basis of the Hall-Williamson plot ${ }^{8)}$ given by Eq. (1).

$$
\beta_{\mathrm{s}} \cos \theta / \lambda=(2 \varepsilon) \sin \theta / \lambda+(K / D)
$$

where $K$ is the Scherrer constant $(=0.9)$, and $\beta_{\mathrm{s}}$ is the true full width at the half maximum height (FWHM) of $K_{\alpha 1}$ lines. Here the FWHM value obtained from three planes (110), (211) and (220) of the bcc phase was used. The spread of the diffracted beams due to the instrument used was measured as the FWHM value $\left(\beta_{\mathrm{r}}\right)$ of $K_{\alpha 1}$ lines of annealed initial iron powder samples as standard samples and was corrected from the FWHM value $\left(\beta_{\mathrm{m}}\right)$ of $K_{\alpha 1}$ lines of mechanically milled iron powders by using the following equation ${ }^{9)}$ :

$$
\beta_{\mathrm{s}}^{2}=\beta_{\mathrm{m}}^{2}-\beta_{\mathrm{r}}^{2}
$$

Thermal analysis was conducted in an argon stream at a heating rate of $0.3 \mathrm{~K} / \mathrm{s}$, using a differential scanning calorimeter (DSC). Hardness was represented by the average of eight measurements in micro-Vickers hardness test (load; 0.245N). Powders buried in an epoxy resin were polished with buff and polishing ceramic paste, and then subjected to hardness testing.

\section{Experimental Results}

\subsection{Microstructural Change of $\mathrm{Y}_{2} \mathrm{O}_{3}$ during Mechan- ical Milling}

Figure 1 shows the $\mathrm{X}$-ray diffraction patterns of an $\mathrm{Fe}-24 \mathrm{mass} \% \mathrm{Cr}-15 \mathrm{mass} \% \mathrm{Y}_{2} \mathrm{O}_{3}$ powder mixture after being mechanically milled for different lengths of time. The iron, chromium, and $\mathrm{Y}_{2} \mathrm{O}_{3}$ powders were blended before the mechanical milling. The mixture reveals bcc diffraction peaks of the iron and chromium powders and a $\mathrm{Y}_{2} \mathrm{O}_{3}$ diffraction peak. The intensity of these diffraction peaks decreases with increasing mechanical milling time. The $\mathrm{Y}_{2} \mathrm{O}_{3}$ diffraction peak disappears after $36 \mathrm{ks}$ of mechanical milling. Accurate lattice parameter measurements confirmed that the alloying of iron and chromium was completed in the $36 \mathrm{ks}$ mechanical milling stage. It was also confirmed that the very same result can be obtained when a prealloyed $\mathrm{Fe}-24 \mathrm{mass} \% \mathrm{Cr}$ alloy powder and a $\mathrm{Y}_{2} \mathrm{O}_{3}$ powder were mixed and mechanically milled. Figure 2 shows TEM images of the $\mathrm{Fe}-24$ mass $\% \mathrm{Cr}-15$ mass $\% \mathrm{Y}_{2} \mathrm{O}_{3}$ powder mixture mechanically milled for $10.8 \mathrm{ks}$ just before the disappearance of the $\mathrm{Y}_{2} \mathrm{O}_{3}$ diffraction peak. X-ray diffraction predicted that the bcc phase particles in the powder would be finely divided to about $140 \mathrm{~nm}$. TEM images of the powder in initial mechanical milling stages exhibit a complicated diffraction contrast. It was difficult to determine the crystalline grain size of the matrix directly from the TEM images. The particles dispersed in the matrix consist of $\mathrm{Y}_{2} \mathrm{O}_{3}$. The dark-field image of the $\mathrm{Y}_{2} \mathrm{O}_{3}$ particles in Fig. 2(b) shows that the $\mathrm{Y}_{2} \mathrm{O}_{3}$ particles are 5 to $20 \mathrm{~nm}$ in size and are incorporated into the matrix of the bcc phase. 


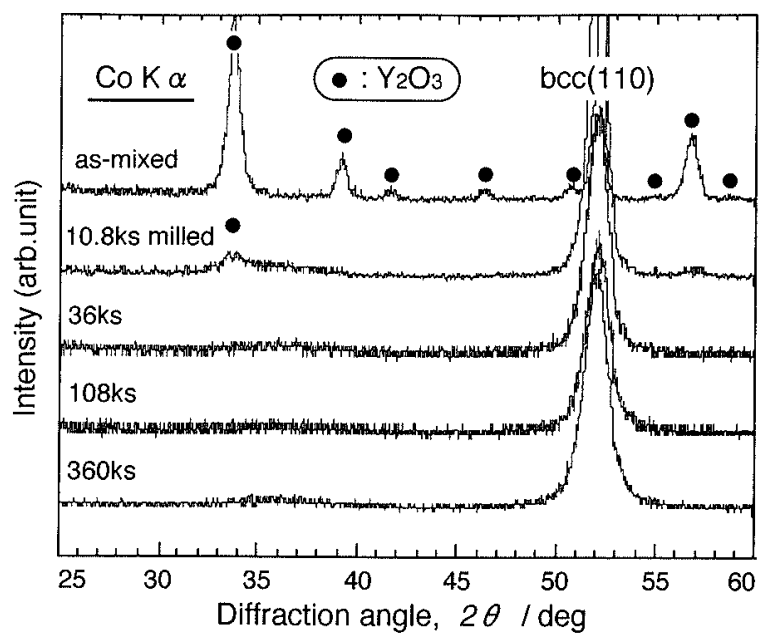

Fig. 1. Variation in $\mathrm{X}$-ray diffraction patterns of an $\mathrm{Fe}$ 24 mass $\% \mathrm{Cl}-15$ mass $\% \mathrm{Y}_{2} \mathrm{O}_{3}$ powder mixture after mechanical milling.

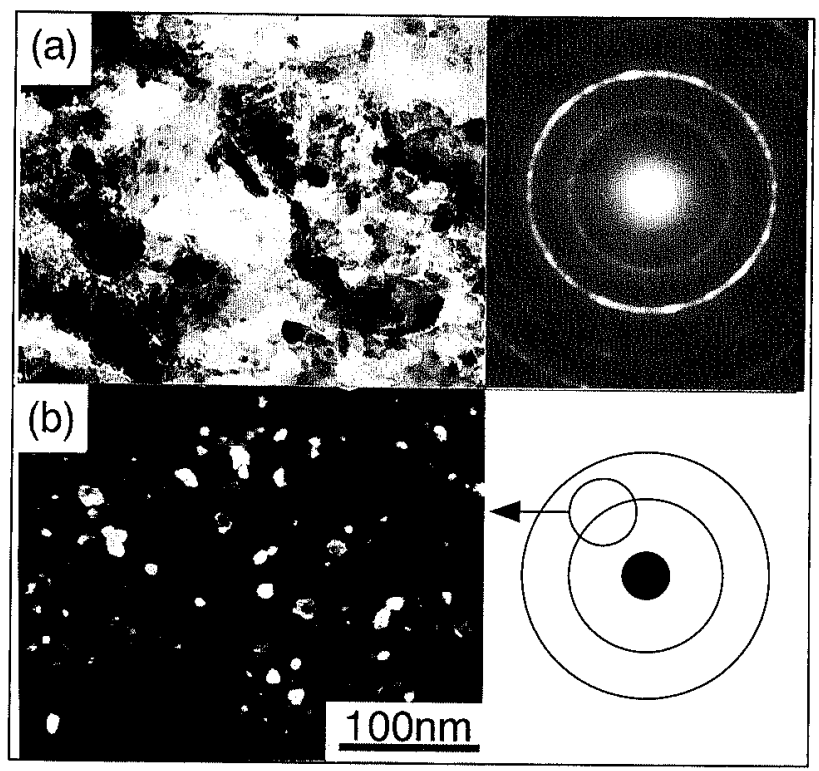

Fig. 2. TEM images of an $\mathrm{Fe}-24$ mass $\% \mathrm{Cr}-15$ mass $\% \mathrm{Y}_{2} \mathrm{O}_{3}$ powder mixture mechanically milled for $10.8 \mathrm{ks}$; bright field image (a), dark field image of $\mathrm{Y}_{2} \mathrm{O}_{3}$ particles (b), and diffraction pattern obtained from the observed areat (a).

This fact shows that the $\mathrm{Y}_{2} \mathrm{O}_{3}$ particles are reduced further in size by mechanical milling because the average size of the $\mathrm{Y}_{2} \mathrm{O}_{3}$ particles in the as-mixed condition is about $50 \mathrm{~nm}$. Figure 3 shows TEM images of the $\mathrm{Fe}-$ 24 mass $\% \mathrm{Cr}-15$ mass $\% \mathrm{Y}_{2} \mathrm{O}_{3}$ powder mixture mechanically milled for $360 \mathrm{ks}$. Fine particles are observed in the bright-field image (a). Analysis of the Debye rings shows that they are not $\mathrm{Y}_{2} \mathrm{O}_{3}$ particles, but ultrafine bcc phase $(\alpha)$ grains. The Debye rings indicate that the ultrafine $\alpha$ grains are distributed in crystallographically random orientations. The measured size of the $\alpha$ grains in the powder in the dark-field image (b), is 10 to $15 \mathrm{~nm}$. The crystallite-size $(D)$ measured by the X-ray diffraction technique is $17 \mathrm{~nm}$, which agrees closely with the $\alpha$ grain size determined by the TEM. The X-ray diffraction technique also confirmed that the $\alpha$ grains have large local strains of $1.1 \%$, which percentage is approxi-

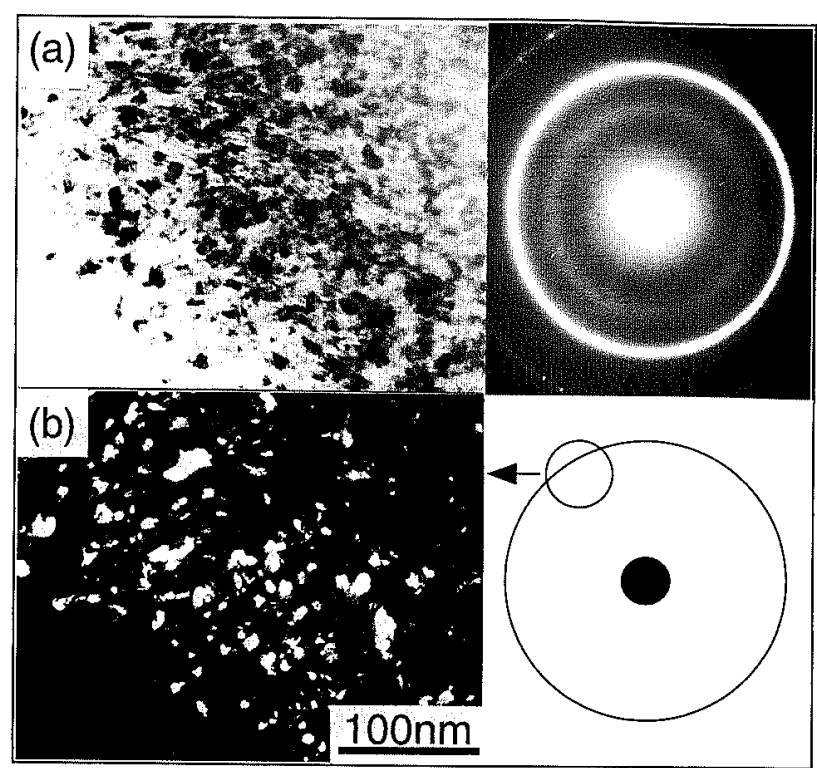

Fig. 3. TEM images of an $\mathrm{Fe}-24 \mathrm{mass} \% \mathrm{Cr}-15$ mass $\% \mathrm{Y}_{2} \mathrm{O}_{3}$ powder mixture mechanically milled for $360 \mathrm{ks}$; bright field image (a), dark field image (b), and diffraction pattern obtained from the selected area of $1.5 \mu \mathrm{m}$ in diameter.

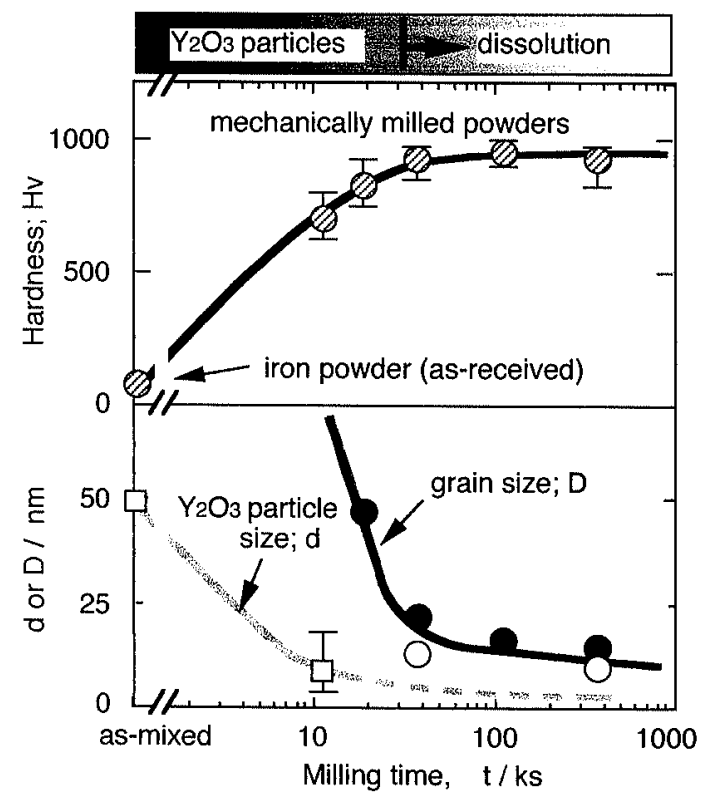

Fig. 4. Changes in hardness, bcc crystalline grain size $(D)$ and $\mathrm{Y}_{2} \mathrm{O}_{3}$ particle size $(d)$ during mechanical milling in an $\mathrm{Fe}-24 \mathrm{mass} \% \mathrm{Cr}-15$ mass $\% \mathrm{Y}_{2} \mathrm{O}_{3}$ powder mixture. For the bcc crystalline grain size $(D)$, the symbols and $O$ show the data obtained by means of X-ray diffractometry and TEM observation, respectively.

mately twice that of martensite in 0.15 mass $\%$ carbon steel (S15C). As for $\mathrm{Y}_{2} \mathrm{O}_{3}$, the presence of $\mathrm{Y}_{2} \mathrm{O}_{3}$ particles could not be ascertained but a halo ring was recognized inside the bcc $\{110\}$ Debye ring by the TEM. Judging from the above results in combination with the results of $\mathrm{X}$-ray diffraction, it is assumed that almost all of the $\mathrm{Y}_{2} \mathrm{O}_{3}$ particles were dissolved in the ultrafine $\alpha$ grain structure. The hardness and average grain size of the $\mathrm{Fe}-24 \mathrm{mass} \% \mathrm{Cr}-15$ mass $\% \mathrm{Y}_{2} \mathrm{O}_{3}$ powder mixture mechanically milled for different lengths of time in relation to the milling time are summarized in Fig. 4. The 


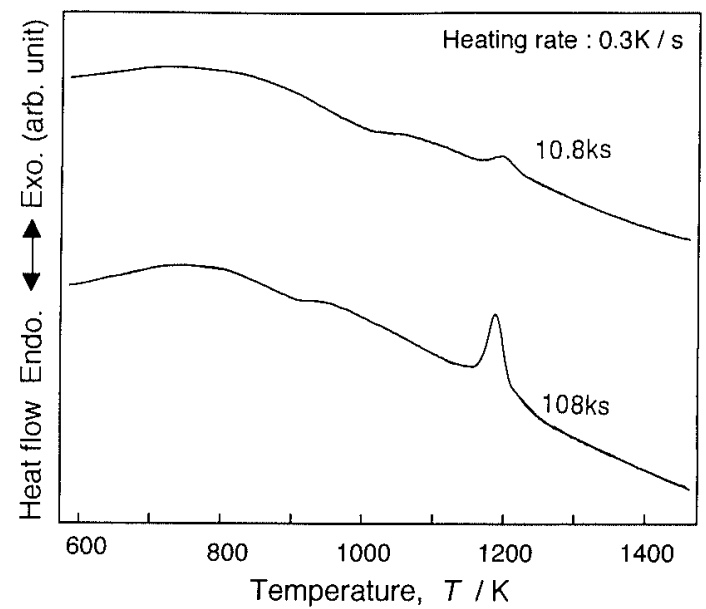

Fig. 5. DSC thermograms of an $\mathrm{Fe}-24$ mass $\% \mathrm{Cr}-15$ mass $\%$ $\mathrm{Y}_{2} \mathrm{O}_{3}$ powder mixture mechanically milled for 10.8 and $108 \mathrm{ks}$.

hardness of the powder mixture mechanically milled for more than $36 \mathrm{ks}$, at which point the $\mathrm{Y}_{2} \mathrm{O}_{3}$ particles disappeared, reach nearly $1000 \mathrm{Hv}$, indicating that work hardening has peaked. In this stage, the grain size of the $\alpha$ matrix reaches about 10 to $20 \mathrm{~nm}$, thus indicating the difficulty of further size reduction. The $\mathrm{Y}_{2} \mathrm{O}_{3}$ particles are so small that it is difficult to ascertain their presence by the TEM. Should they remain, they may be a few nanometers in size.

\subsection{Reprecipitation of Decomposed $\mathrm{Y}_{2} \mathrm{O}_{3}$}

Figure 5 shows DSC thermal analysis curves of the $\mathrm{Fe}-24 \mathrm{mass} \% \mathrm{Cr}-15$ mass $\% \mathrm{Y}_{2} \mathrm{O}_{3}$ powder mixture mechanically milled for $10.8 \mathrm{ks}$ and with the $\mathrm{Y}_{2} \mathrm{O}_{3}$ peak remaining and of the $\mathrm{Fe}-24$ mass $\% \mathrm{Cr}-15 \mathrm{mass} \% \mathrm{Y}_{2} \mathrm{O}_{3}$ powder mixture mechanically milled for $108 \mathrm{ks}$ and with the $\mathrm{Y}_{2} \mathrm{O}_{3}$ peak completely disappearing. An exothermic peak is recognized in the vicinity of $1200 \mathrm{~K}$ on each curve. The amount of heat generation is greater for the $\mathrm{Fe}-24 \mathrm{mass} \% \mathrm{Cr}-15$ mass $\% \mathrm{Y}_{2} \mathrm{O}_{3}$ powder mixture mechanically milled for $108 \mathrm{ks}$ and with the $\mathrm{Y}_{2} \mathrm{O}_{3}$ peak completely disappearing. Figure 6 shows the X-ray diffraction patterns of the $\mathrm{Fe}-24$ mass $\% \mathrm{Cr}-15$ mass $\%$ $\mathrm{Y}_{2} \mathrm{O}_{3}$ powder mixtures mechanically milled for $360 \mathrm{ks}$ and annealed for $3.6 \mathrm{ks}$ at different temperatures. The powder mixture annealed at temperatures of under $1200 \mathrm{~K}$ reveals no marked changes as compared with the as-milled powder mixture. The powder mixture annealed at temperatures of $1273 \mathrm{~K}$ and above exhibit diffraction peaks indicating the presence of oxides such as $\mathrm{YCrO}_{3}$ and $\mathrm{Y}_{2} \mathrm{O}_{3}$. That is, the exothermic peaks evident in the vicinity of $1200 \mathrm{~K}$ in the thermal analysis curves of Fig. 5 indicate that $\mathrm{Y}_{2} \mathrm{O}_{3}$ particles that decomposed in the mechanical milling process reprecipitated as $\mathrm{YCrO}_{3}$ and $\mathrm{Y}_{2} \mathrm{O}_{3}$. Figures 7(a) and 7(b) show TEM images of the $\mathrm{Fe}-24 \mathrm{mass} \% \mathrm{Cr}-15$ mass $\% \mathrm{Y}_{2} \mathrm{O}_{3}$ powder mixture mechanically milled for $360 \mathrm{ks}$ and annealed at 1073 and $1273 \mathrm{~K}$, respectively. As compared with the as-milled powder mixture shown in Fig. 3, the powder mixture annealed at $1073 \mathrm{~K}$ is somewhat relaxed in strains and is microstructurally clear, but its grain growth is not so conspicuous. In the electron diffraction pattern, the same

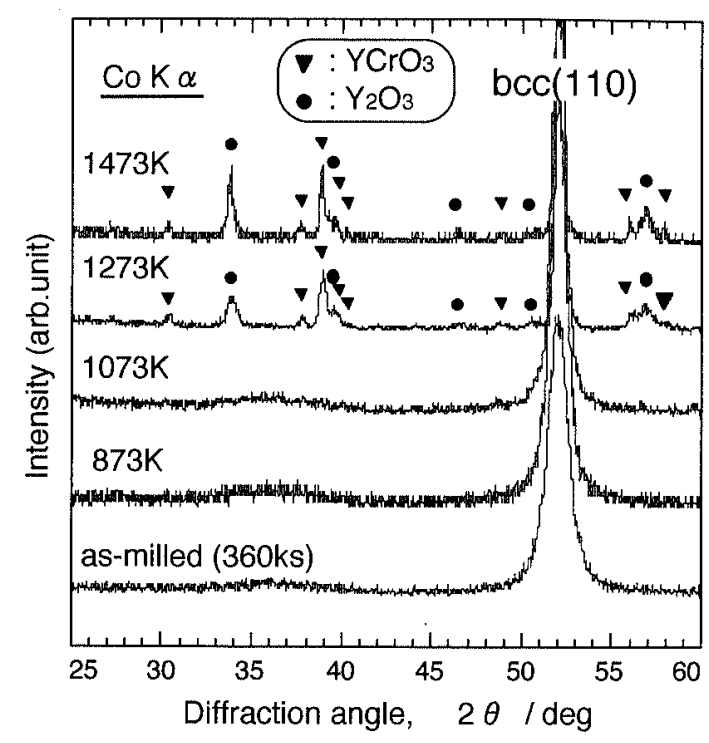

Fig. 6. Variation in X-ray diffraction pattern with $3.6 \mathrm{ks}$ isochronal annealing in an $\mathrm{Fe}-24$ mass $\% \mathrm{Cr}-15$ mass $\%$ $\mathrm{Y}_{2} \mathrm{O}_{3}$ powder mixture mechanically milled for $360 \mathrm{ks}$.

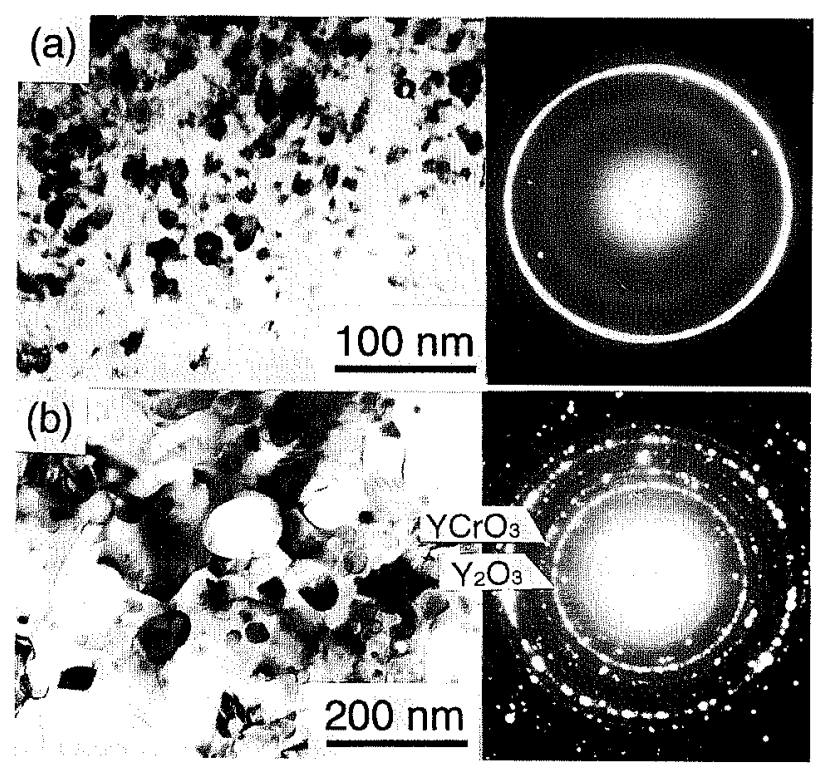

Fig. 7. TEM images showing the microstructural change after $3.6 \mathrm{ks}$ isochronal annealing at $1073 \mathrm{~K}$ (a) and $1273 \mathrm{~K}$ (b) for an $\mathrm{Fe}-24$ mass $\% \mathrm{Cr}-15$ mass $\% \mathrm{Y}_{2} \mathrm{O}_{3}$ powder mixture mechanically milled for $360 \mathrm{ks}$. Diffraction patterns were obtained from the selected area of $1.5 \mu \mathrm{m}$ in diameter.

halo ring as shown in Fig. 3 is observed inside of the bcc $\{110\}$ Debye ring. In the powder mixture annealed at $1273 \mathrm{~K}$ (b), not only are observed oxide particles, but also the $\alpha$ grains in the matrix are markedly coarsened. The average particle size of the oxides is $30 \mathrm{~nm}$. Figure 8 shows the effect of the annealing temperature on the hardness, $\alpha$ grain size and local strain of the $\mathrm{Fe}-$ $24 \mathrm{mass} \% \mathrm{Cr}-15 \mathrm{mass} \% \mathrm{Y}_{2} \mathrm{O}_{3}$ powder mixture mechanically milled for $360 \mathrm{ks}$ and annealed at different temperatures. It should be noted here that ultrafine $\alpha$ grains of about $20 \mathrm{~nm}$ are stably retained without a significant growth until the temperature at which the reprecipitation of oxides occurs is reached and that the reprecipitation of oxides triggers rapid coarsening of the $\alpha$ grains. Local 


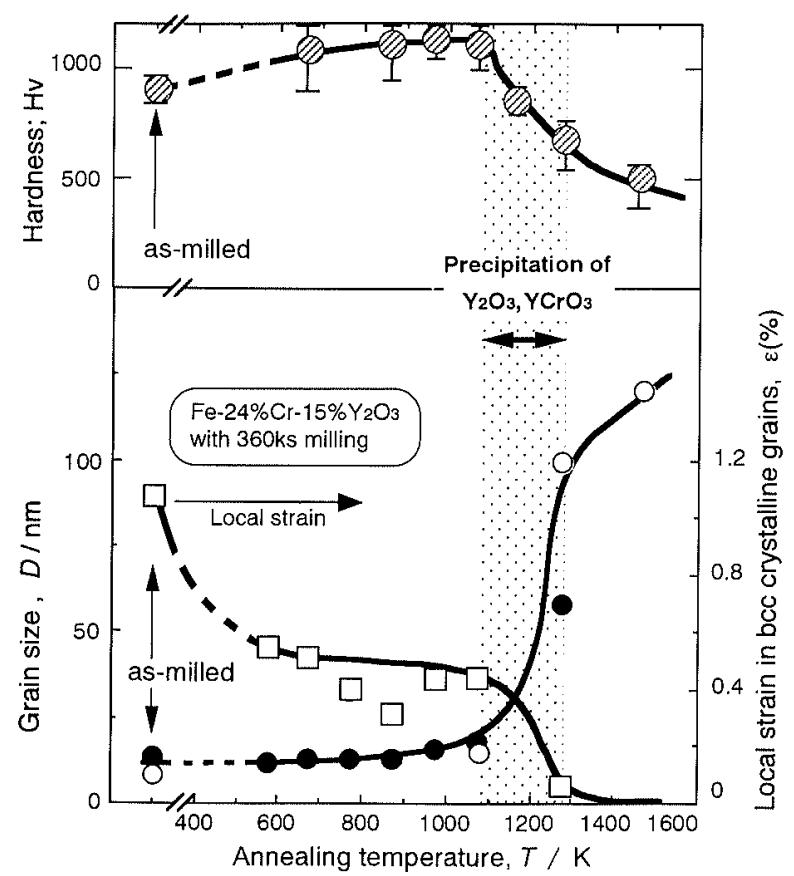

Fig. 8. Changes in hardness, bce crystalline grain size $(D)$ and local strain $(\varepsilon)$ after $3.6 \mathrm{ks}$ isochronal annealing in an $\mathrm{Fe}-24 \mathrm{mass} \% \mathrm{Cr}-15 \mathrm{mass} \% \mathrm{Y}_{2} \mathrm{O}_{3}$ powder mixture mechanically milled for $360 \mathrm{ks}$. For the bec crystalline grain size, the symbols - and $O$ show the data obtained by means of X-ray diffractometry and TEM observation, respectively,

strains of about $0.5 \%$ remain in the powders annealed at temperatures from 600 to $1100 \mathrm{~K}$, but almost disappear after reprecipitation of oxides. The hardness of the powder mixture slightly increases at temperatures below the oxide reprecipitation temperature. In the oxide reprecipitation temperature region, the powder mixture noticeably softens in response to coarsening of the matrix $\alpha$ grains.

\section{Discussion}

\subsection{Destination of Dissolved Yttrium and Oxygen Atoms in Nanocrystalline $\alpha$ Grain Structure}

As the yttrium and oxygen atoms rejected by the decomposition of $\mathrm{Y}_{2} \mathrm{O}_{3}$ are dissolved substitutionally and interstitially in the bcc crystalline lattice, respectively, they greatly distort the crystalline lattice. Whether or not the yttrium and oxygen atoms are dissolved in the bcc crystalline lattice can be thus judged from the change in the lattice parameter. Figure 9 shows the lattice parameter of the bcc crystalline lattice of the $\mathrm{Fe}-$ 24 mass $\% \mathrm{Cr}$ powder mixture mechanically milled for $360 \mathrm{ks}$ and ranging from 0 to 15 mass $\%$ in the $\mathrm{Y}_{2} \mathrm{O}_{3}$ content. The broken line indicates the change in the lattice parameter (Vegard's law) expected to occur when all of the yttrium atoms rejected by the decomposition of $\mathrm{Y}_{2} \mathrm{O}_{3}$ are assumed to substitutionally enter into a solid solution in the bcc crystalline lattice. The lattice parameter of the milled powder is constant, irrespective of the $\mathrm{Y}_{2} \mathrm{O}_{3}$ content, and is only slightly greater than that of pure

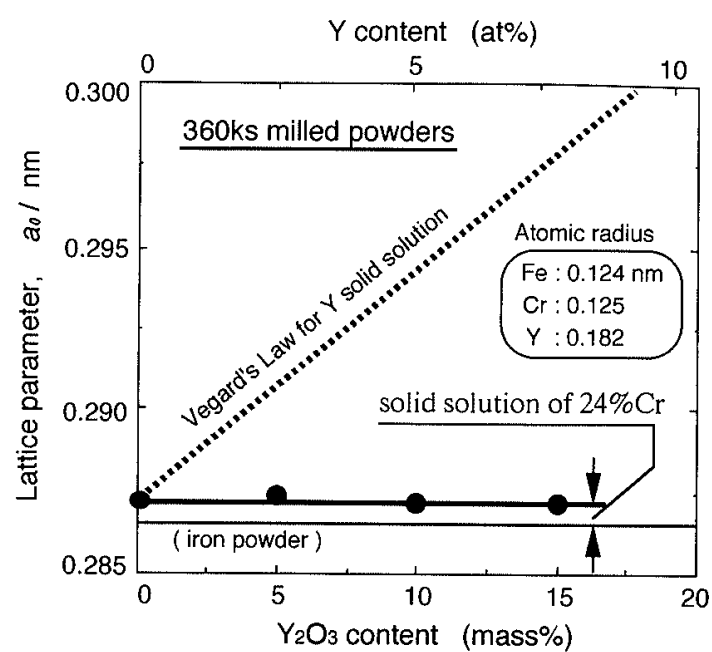

Fig. 9. Relation between lattice parameter of bec crystalline grains and $\mathrm{Y}_{2} \mathrm{O}_{3}$ content in an $\mathrm{Fe}-24$ mass $\% \mathrm{Cr}$ 15 mass $\% \mathrm{Y}_{2} \mathrm{O}_{3}$ powder mixture mechanically milled for $360 \mathrm{ks}$

iron. This increase in the lattice parameter is due to the complete dissolution of the 24 mass \% chromium and satisfies Vegard's law concerning the dissolution of chromium atoms. The possibility of oxygen atoms going into a solid solution was determined in the same manner. It was confirmed as a result of this determination that few oxygen atoms were dissolved in the bcc crystalline lattice. When such a powder mixture was annealed at $1300 \mathrm{~K}$ or less, the lattice parameter was practically constant. This suggests that few yttrium and oxygen atoms move in and out of the bcc crystalline lattice during annealing. Figure 10 shows a FE-TEM image and EDS spectra of the $\mathrm{Fe}-24 \mathrm{mass} \% \mathrm{Cr}-15 \mathrm{mass} \% \mathrm{Y}_{2} \mathrm{O}_{3}$ powder mixture mechanically milled for $360 \mathrm{ks}$. Since the powder mixture had strains in the as-milled condition too high to produce a clear image, it was annealed at $973 \mathrm{~K}$ for $3.6 \mathrm{ks}$ to relieve the strains. The $\alpha$ grains are so small that they overlap in the thickness direction of the specimen, making it difficult to clearly distinguish between the $\alpha$ grains and the grain boundaries. The area where atoms are arranged in an orderly way (as indicated by the arrow (a) and called the lattice area) and the area where atoms are arranged in a disorderly way (as indicated by the arrow (b) and called the interfacial area) can be approximately identified. The electron diffraction patterns (beam diameter of $1 \mathrm{~nm}$ ) of the two areas are compared. The diffraction spots from the bce crystalline lattice are clear in the lattice area (a), and the halo ring inside of the bcc $\{110\}$ spots is noticeable in the interfacial area (b). As evident from the EDS spectra, while yttrium and oxygen are detected in the lattice area (a), ${ }^{*}$ the yttrium and oxygen peak intensities are higher in the interfacial area (b). Many similar analyses were made, and similar results were obtained. Given the absence of yttrium and oxygen atoms in the bcc crystalline lattice, it can be concluded that most of the yttrium and oxygen atoms exist at the boundaries of the $\alpha$ grains that are finely divided to about $10-20 \mathrm{~nm}$.

\footnotetext{
* This is probably due to the overlap of the bec crystalline lattice area and the grain boundary area.
} 

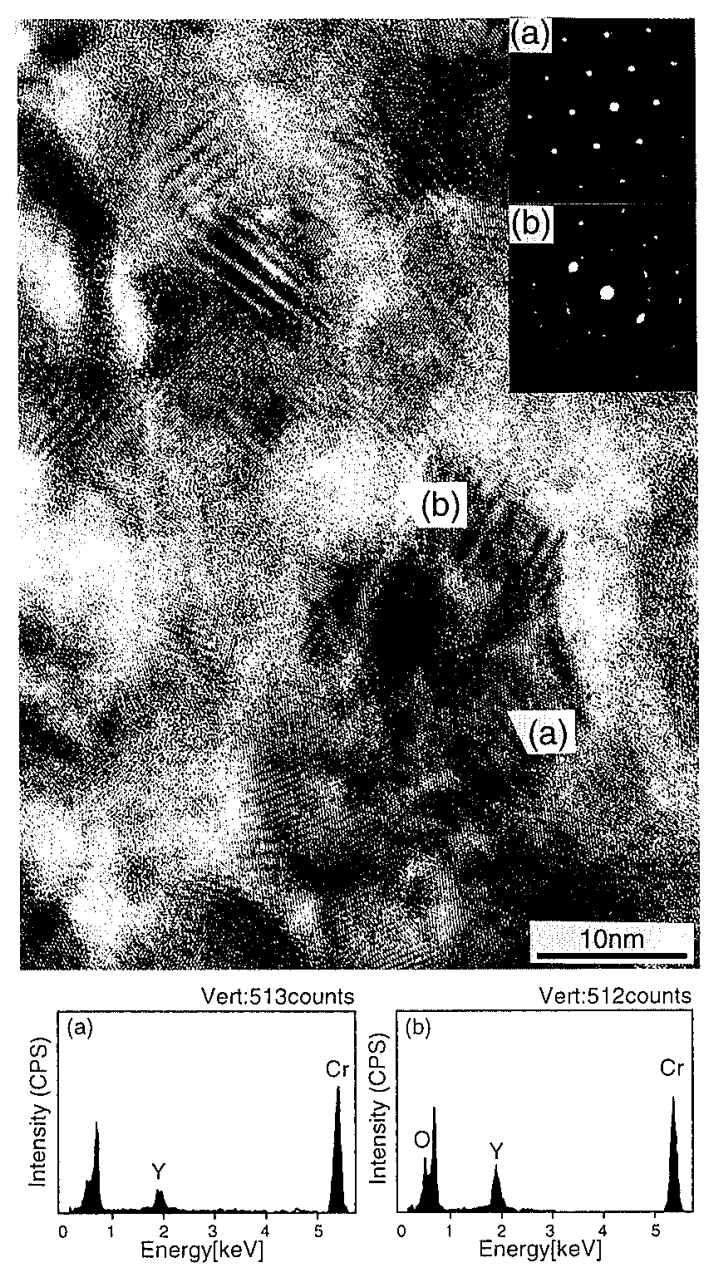

Fig. 10. FE-TEM images of an $\mathrm{Fe}-24 \mathrm{mass} \% \mathrm{Cr}-15 \mathrm{mass} \%$ $\mathrm{Y}_{2} \mathrm{O}_{3}$ powder mixture; annealed at $973 \mathrm{~K}$ for $3.6 \mathrm{ks}$ after mechanical milling of $360 \mathrm{ks}$. Diffraction patterns and the results of EDS analysis for the crystalline area (a) and disordered area (b) are also shown.

The fact that halo rings are obtained in the powder mixture in which the $\mathrm{Y}_{2} \mathrm{O}_{3}$ particles are decomposed, especially from the interfacial areas, indicates that the grain-boundary layers where yttrium and oxygen are dissolved are amorphous in structure. Figure 11 schematically illustrates the microstructure of an alloy composed of nanocrystalline grains and a grain boundary amorphous layer. The nanocrystalline grain structure formed by mechanical milling is reported to be characteristic of a dislocation-free nanocrystalline grains despite heavy working, and wavy grain boundaries. ${ }^{10)}$ On the present alloy, the internal structure is considered to be such nanocrystalline $\alpha$ grains of an irregular shape which are surrounded by an amorphous phase. This nanocrystalline grain structure is very similar to that of mesoscopic multiphase alloys produced from amorphous state. ${ }^{11-13)}$ In a mesoscopic multi-phase alloy, nanocrystalline grains rapidly grow upon crystallization of the amorphous phase (this crystallization is called polymorphous crystallization ${ }^{14)}$ ). Below the crystallization temperature, however, the growth of the nanocrystalline grains is known to be inhibited by the remaining amorphous phase. ${ }^{11-13)}$ The present alloy can be accurately explained by the hypothesis that the

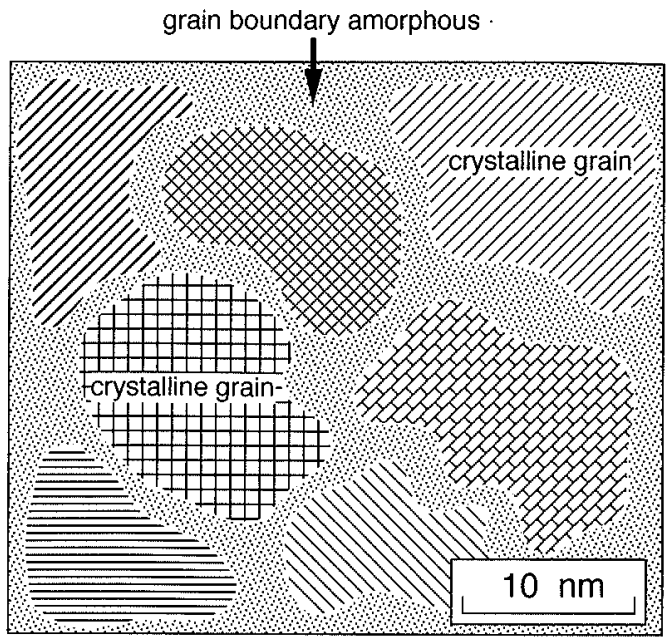

Fig. 11. Model of the mixed structure composed of nanocrystalline grains and a grain boundary amorphous layer.

growth of the nanocrystalline $\alpha$ grains below $1200 \mathrm{~K}$ is inhibited by the amorphous phase of the grain boundary layers.

In general, local strains are thought to come from the dislocations within matrix. But, in the present nanocrystalline alloy, most of the local strains should come from the area near grain boundaries, where nano-scaled lattice distortion and the geometrically-necessary dislocation ${ }^{15)}$ exist to accommodate the misfit of grain boundaries in the nanocrystalline grain structure. For the lattice distortion, Valiev et al. ${ }^{16)}$ have shown in ultra fine grained materials produced through severe plastic deformation by equal-channel angular pressing (ECAP) etc. that an elastically distorted layer exists just near grain boundaries. Assuming that grain boundary thickness of a nanocrystalline material is about $1 \mathrm{~nm}^{17)}$ (equivalent to the thickness of four iron atoms), the volume fraction of the grain boundary layer is estimated to be so large as a few tens of percent, that the strains near grain boundaries become a large value in total and a part of strains should remain even after annealing for accommodating the misfit of grain boundaries, as described with respect to Fig. 8 .

\subsection{Conditions for Dissolution of Oxides}

The precipitation or dissolution of a second phase requires some driving force. Concerning the dissolution of particles during the super-heavy deformation of metals, the authors proposed, assuming that the grain boundaries are the sites that receive rejected atoms, the decrease in chemical free energy after grain boundary segregation and the increase in interfacial energy after the size reduction of particles as such driving forces, and maintained that the ultrafine size reduction of the matrix grains is an indispensable condition for increasing the area of grain boundaries as sites to receive atoms rejected by the decomposition of the second phase. ${ }^{18)}$ The decrease in chemical free energy after grain boundary segregation is supposed to vary greatly depending on the particles to be decomposed. The increase in interfacial energy after the size reduction of 


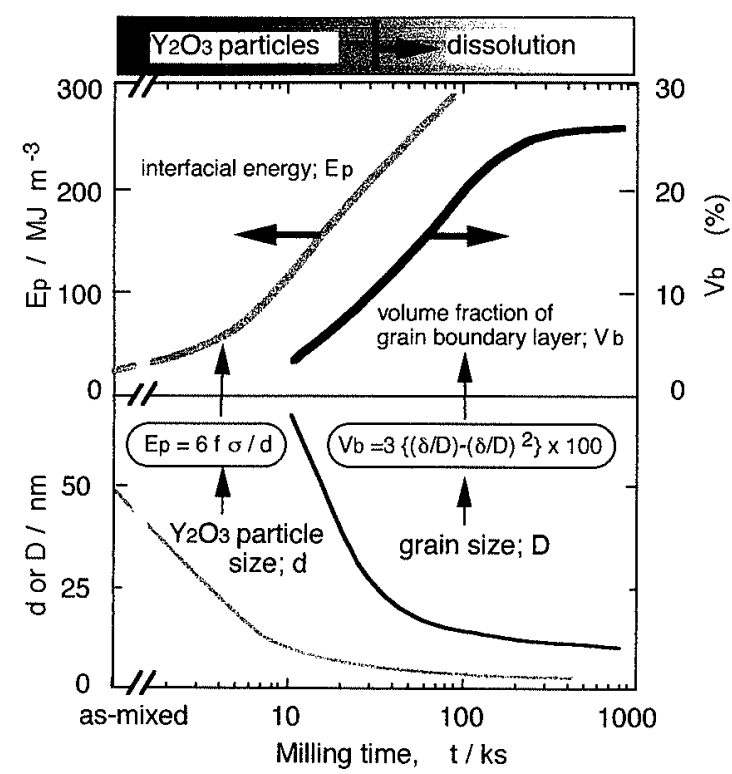

Fig. 12. Changes in the total interfacial energy $(E p)$ and the volume fraction of a grain boundary layer $(V b)$ as a function of milling time, which were evaluated in terms of $\mathrm{Y}_{2} \mathrm{O}_{3}$ particle size $(d)$ and bec crystalline grain size $(D)$, respectively, based on the formulas given in the figure. The characters $f, \sigma$ and $\delta$ in the formulas denote the volume fraction of $\mathrm{Y}_{2} \mathrm{O}_{3}$ particles, interfacial energy per unit area and the thickness of the grain boundary layer, respectively.

particles alone is considered to be a driving force for the decomposition of particles. The possibility of the dissolution of particles is studied in relation to the size reduction of crystalline grains. In Fig. 12, the changes in the volume fraction $V b$ of grain boundary layers and the interfacial energy $E p$ as calculated by the equations given are shown in relation to the mechanical milling time, based on the bcc crystalline grain size $D$ and the $\mathrm{Y}_{2} \mathrm{O}_{3}$ particle size $d$ of mechanically milled powder mixtures. At the mechanical milling time of nearly $36 \mathrm{ks}$ at which the $\mathrm{Y}_{2} \mathrm{O}_{3}$ particles disappear, the interfacial energy approximately increases tenfold compared with that at the as-mixed condition, and the volume fraction of the grain boundary layers reaches about $10 \%$. Whether or not the grain boundary layers in this volume fraction can dissolve all of the atoms rejected from the particles cannot be definitely determined, because the solubility limit of the atoms at the grain boundaries also as to be considered. If the element in question is readily dissolvable in large amounts at the grain boundaries, it is assumed that its rejected atoms are all received at the grain boundaries. When the particles decompose to form amorphous grain boundary layers, the increase in the number of amorphous grain boundary layers also increases the total number of atoms that can be absorbed. This points to the possibility of more particles dissolving.

\section{Conclusions}

The microstructural change of $\mathrm{Y}_{2} \mathrm{O}_{3}$ in $\mathrm{Fe}-24$ mass $\%$ $\mathrm{Cr}-0-15 \mathrm{mass} \% \mathrm{Y}_{2} \mathrm{O}_{3}$ powder mixture during mechanical milling and annealing was clarified, and its relationship with the internal structure of the powder mixture was investigated. The following findings were obtained as a result:

(1) Mechanical milling for $36 \mathrm{ks}$ or more was long enough to allow the mechanical alloying of the iron and chromium powders.

(2) In the mechanical milling process, the $\mathrm{Y}_{2} \mathrm{O}_{3}$ particles are gradually fractured with the grain refining in the $\alpha$ matrix. As the matrix $\alpha$ grains reach a size of about $20 \mathrm{~nm}$, most of the $15 \mathrm{mass} \% \mathrm{Y}_{2} \mathrm{O}_{3}$ are decomposed. The resultant mixture markedly hardens to about $1000 \mathrm{Hv}$.

(3) The mechanically milled powder mixture with the $\mathrm{Y}_{2} \mathrm{O}_{3}$ particles decomposing, oxides like $\mathrm{YCrO}_{3}$ and $\mathrm{Y}_{2} \mathrm{O}_{3}$ reprecipitated in the temperature region in the vicinity of $1200 \mathrm{~K}$.

(4) The ultrafine $\alpha$ grains produced by mechanical milling are retained without marked grain growth until the reprecipitation of the oxides $\mathrm{YCrO}_{3}$ and $\mathrm{Y}_{2} \mathrm{O}_{3}$ takes place, and rapidly grow as the oxides $\mathrm{YCrO}_{3}$ and $\mathrm{Y}_{2} \mathrm{O}_{3}$ reprecipitate.

(5) The decomposition of $\mathrm{Y}_{2} \mathrm{O}_{3}$ can be explained by the formation of amorphous grain boundary layers enriched in yttrium and oxygen atoms. As a result, it is considered to be necessary for the dissolution of $\mathrm{Y}_{2} \mathrm{O}_{3}$ to refine the matrix $\alpha$ grains to a nanometric size, because the grain boundary layers in a sufficient volume fraction is required for the dissolution of atoms rejected from the decomposed $\mathrm{Y}_{2} \mathrm{O}_{3}$. Besides, $\mathrm{Y}_{2} \mathrm{O}_{3}$ particles should be crushed to a few nanometers to produce the driving force for the decomposition.

\section{REFERENCES}

1) J. S. Benjamin: Metall. Trans., 1 (1970), 2943

2) R. C. Klug, G. Krauss and D. K. Matlock: Metall. Mater. Trans. A, 27A (1996), 1945.

3) J. S. Benjamin and M. J. Bomford: Metall. Trans. A, 8A (1977), 1301 .

4) A. Alamo, H. Regle, G. Pons and J. L. Bechade: Mater. Sci. Fortum, 88-90 (1992), 183

5) S. Nomura, T. Okuda, S. Shikakura, M. Fujiwara and K. Asabe: Proc. Int. Symp. Solid State Powder Processing, ed, by A. H. Clauer and J. J. deBarbadillo, The Minerals, Metals \& Materials Society, Warrendale, (1989), 203.

6) K. Ameyama, O. Okada, K. Hirai and N. Nakabo: Mater. Trans., $J M, 36$ (1995), 269.

7) W. A. Rachinger: J. Sci. Instr., 25 (1948), 254

8) G. K. Williamson and W. H. Hall: Acta Metall, 1 (1953), 22.

9) B. E. Warren and J. Biscoe: J. Am. Ceram. Soc., 21 (1938), 49

10) K. Ameyama, M. Hiromitsu and N. Imai: Tetsu-to-Hagané, 84 (1998), 357.

11) A. Inoue: Materia Japan, 34 (1995), 934

12) K. Hono and T. Sakurai: Materia Japan, 35 (1996), 843.

13) Y. Zhang, K. Hono, A. Inoue, A. Makino and T. Sakurai: Acta Mater., 44 (1996), 1497.

14) U. Herold and U. Köster: Proc. 3rd Int. Conf. Rapidly Quenched Metals, ed. by B. Cantor, Brighton, Metals Society, London, (1978), 281

15) M. F. Ashby: Philos. Mag., 21 (1970), 399

16) R. Z. Valief, A. V. Korznikov and R. R. Mulyukov: Mater. Sci. Eng., Al68 (1993), 141.

17) C. Suryanarayana: Inl. Mater. Rev., 40 (1995), 41.

18) S. Takaki and Y. Kimura: Proc. Int. Conf. Thermomechanical Processing Steels \& Other Materials (THERMEC'97), ed. by T. Chandra and T. Sakai, The Minerals, Metals \& Materials Society, Warrendale, (1997), 281. 